\title{
Effect of the Er, Cr: YSGG Laser Parameters on Shear Bond Strength and Microstructure on Human Dentin Surface
}

\author{
Eun Mi Rhim¹, Sungyoon Huh², Duck Su Kim³, Sun-Young Kim, \\ Su-Jin Ahn ${ }^{5}$, Kyung Lhi Kang6 and Sang Hyuk Park ${ }^{4,7}$ \\ ${ }^{1}$ The Catholic University of Korea, St. Paul's Hospital, \\ Dept. of Conservative Dentistry, Seoul, \\ ${ }^{2}$ Shingu University, Dept. of Dental Hygiene, Seongnam, \\ ${ }^{3}$ Kyung Hee University, Dental Hospital, Dept. of Conservative Dentistry, Seoul \\ ${ }^{4}$ Kyung Hee University, Dept. of Conservative Dentistry, Seoul, \\ ${ }^{5}$ Kyung Hee University, Dental Hospital at Gandong, \\ Dept. of Biomaterials \& Prosthodontics, \\ ${ }^{6}$ Kyung Hee University, Dental Hospital at Gandong, Dept. of Periodontology, \\ ${ }^{7}$ Kyung Hee University Dental Hospital at Gandong, Dept. of Conservative Dentistry \\ Korea
}

\section{Introduction}

The developments of laser technology have enabled their use in multiple dental procedures, such as soft tissue operations, composite restorations, tooth bleaching, root canal irrigation, caries removal and tooth preparations with minimal pain and discomfort (Turkmen et al., 2010) Recently, the Er,Cr:YSGG laser was recommended for minimally invasive purposes due to its precise ablation of the enamel and dentin without side-effects to the pulp and surrounding tissues. It has a 2780-nm wavelength and absorbed strongly by both water and hydroxyapatite. The sudden evaporation of bound water causes micro-explosions that blast away tiny particles of the tooth (Obeidi et al., 2010).

Previous studies reported that irregularities and the crater-shaped appearance of ablated dentin was comparable to the dentine surface after acid etching, which might promote micromechanical interlocking between dental restorative materials and the tooth surface (Visuri et al., 1996; Armengol et al., 1999; Martínez-Insua et al., 2000; Carrieri et al., 2007; Gurgan et al., 2008). Despite its efficiency, reports on the bond strengths of composite resin to a tooth substrate prepared by a laser are often confusing and contradictory. Some studies reported higher bond strengths to laser-prepared dentin than to acid-etched dentin (Visuri et al., 1996; Carrieri et al., 2007). Others have reported significantly lower bond strengths on laser preparation (Armengol et al., 1999; Martínez-Insua da Silva Dominguez et al. 2000; Gurgan Kiremitci et al. 2008) and others have reported no significant differences (Abdalla \& Davidson, 1998).

Generally there are three adhesive systems. The first uses $30-40 \%$ phosphoric acid to remove the smear layer (etch-and-rinse (ER) technique). This bonding mechanism to dentin 
depends on the hybridization of the resin within the exposed collagen mesh as well as to the dentin tubules (Abdalla \& Davidson, 1998), creating a micromechanical interlocking of the resin within the exposed collagen fibril scaffold. The second is the "self-etch" adhesives (SEA) which employs acidic monomers that simultaneously condition and prime dentin. The smear layer remains partially but is used to hybridize with the underlying dentin (Perdigao et al., 2000). The last is an all-in-one system, but the stability of the bond strength decreases with time by because it contains many hydrophilic monomers.

According to previous reports, a tiny flake surface formed by the laser irradiation of dentin can be removed with 30-40\% acid etching, but the primer of SEA cannot. This study hypothesized that the primer of SEA cannot improve the free surface energy of irradiated dentin. Therefore, it is unable to make a proper environment for sufficient bond strength. The null hypothesis was that the shear bond strength with "self-etch" adhesives (SEA) did not show a difference from that with the etch-and-rinse (ER) technique after a pretreatment with a laser in dentin.

This study examined the shear bond strength of a hybrid composite resin bonded with two different adhesive systems to the dentin surfaces prepared with Er,Cr:YSGG laser etching, and evaluated the morphologic structure of de-bonded dentin surface after Shear Bond Strength (SBS) Test by scanning electron microscopy.

\section{Materials and methods}

\subsection{Tooth preparation}

Tables 1 and 2 list the materials used in this study and the study design, respectively. Twenty four freshly extracted caries and restoration-free permanent human molars stored in distilled water were used. The teeth were embedded in improved stone with the occlusal surface of the crown exposed and parallel to the base of the stone, and the embedded teeth were sectioned at one third of the occlusal surfaces to expose the dentin surface. Each tooth was wet-ground with 320 -grit silicon carbide paper and polished with 1200 -grit to obtain a flat dentin surface. The specimens were stored in distilled water at $37^{\circ} \mathrm{C}$. The teeth were divided randomly into two groups, control and laser irradiated groups. The control groups without laser irradiation were divided randomly into two subgroups (SE bond and Single bond), and the laser irradiated groups were divided into four subgroups (SE bond with 1.4 $\mathrm{W}, 2.25 \mathrm{~W}$ and Single bond with $1.4 \mathrm{~W}, 2.25 \mathrm{~W})$.

\subsection{Laser irradiation}

The Er,Cr:YSGG laser (Waterlase, BioLase Technology, Inc., San Clemente, CA) with a 2780 nm wavelength and $20 \mathrm{~Hz}$ of power with a sapphire tip was used. Laser irradiation was performed on the dentin surface with either $1.4 \mathrm{~W}$ or $2.25 \mathrm{~W}$. The flattened dentin surfaces of the teeth were irradiated at $90^{\circ}$ in non-contact mode with a fixed distance of $6 \mathrm{~mm}$ away from the laser tip in a sweeping motion to achieve an even surface coverage by overlapping the laser impact. The laser handpiece was attached to a modified surveyor to ensure a consistent energy density, spot size, distance and handpiece angle.

\subsection{Bonding procedures}

In all groups, including laser irradiated groups and control groups, the bonding procedures recommended by the manufacturer' instruction were followed strictly. In the single bond 
adhesive system, etching procedures were conducted using $37 \%$ phosphoric acid (3M ESPE, St. Paul, MN, USA) for 15 seconds followed by rinsing with a water spray for 15 seconds, and blot dried, and bonded and light curing for 15 seconds. In the Clearfil SE bond system, a primer was applied to the dentin surface for 10 seconds followed by bonding and light curing, as shown table 1 .

After light curing the bonding resin, a Teflon tube (GI tech, Seoul, Korea) with an inner diameter of $2 \mathrm{~mm}$ and a height of $2 \mathrm{~mm}$ was attached to each dentin surface and filled with A3 Body Shade of the hybrid composite Resin (Filtek Supreme Plus 3 M ESPE, MN, USA) followed by light curing for $40 \mathrm{~s}$. After light curing, the teeth were stored in water at $37^{\circ} \mathrm{C}$ for $24 \mathrm{~h}$ before the Shear Bond Strength (SBS) Test.

\begin{tabular}{|l|l|l|l|l|}
\hline Brand name & Manufacturer & Material type & Composition & $\begin{array}{l}\text { Application } \\
\text { procedure }\end{array}$ \\
\hline $\begin{array}{l}\text { Clearfil SE } \\
\text { bond }\end{array}$ & $\begin{array}{l}\text { Kuraray, Tokyo, } \\
\text { Japan }\end{array}$ & $\begin{array}{l}\text { Self etching } \\
\text { adhesive system }\end{array}$ & $\begin{array}{l}\text { Primer: MDP, } \\
\text { HEMA, N,N- } \\
\text { Diethanol p- } \\
\text { toluidine, water } \\
\text { Bonding resin: } \\
\text { Bis-GMA, CQ, } \\
\text { HEMA, MDP, } \\
\text { Micro filler }\end{array}$ & $\begin{array}{l}\text { Apply primer } \\
\text { and leave 20 } \\
\text { seconds, air } \\
\text { blow, apply } \\
\text { bonding system }\end{array}$ \\
& MN, USA & $\begin{array}{l}\text { Bis-GMA, HEMA, } \\
\text { Water, UDMA, } \\
\text { Ethanol, } \\
\text { Polyalkenoic acid } \\
\text { copolymer }\end{array}$ & $\begin{array}{l}\text { Acid-etch for 15 } \\
\text { seconds, rinse, } \\
\text { apply adhesive, } \\
\text { gentle air blow, } \\
\text { light curing for } \\
10 \text { seconds. }\end{array}$ \\
\hline
\end{tabular}

Table 1. Materials used in this study.

\begin{tabular}{|c|c|c|}
\hline \multirow{2}{*}{ Laser intensity } & \multicolumn{2}{|c|}{ Adhesive system } \\
\cline { 2 - 3 } & Single bond & SE bond \\
\hline Control (no laser) & Group A & Group D \\
\hline $1.4 \mathrm{~W}$ & Group B & Group E \\
\hline $2.25 \mathrm{~W}$ & Group C & Group F \\
\hline
\end{tabular}

Table 2. Classification of the experimental groups.

\subsection{Shear Bond Strength (SBS) test}

Before loading, the tube mold was removed carefully with a sharp blade and the specimens were then placed in a custom-made fixture mounted on a Universal Testing Machine (INSTRON Model 5562, Norwood, MA). The specimens were loaded to failure under 
compression using a knife-edge loading head at a cross-head speed of $1 \mathrm{~mm} / \mathrm{min}$. The investigator, who was blinded to the group treatment, performed the load testing procedure. The maximum load to failure was recorded for each sample and the Shear bond strength (SBS) was expressed in megapascals $(\mathrm{MPa})$, which was derived by dividing the imposed force (Newtons) by the bonded area $\left(\mathrm{mm}^{2}\right)$.

\subsection{SEM evaluation}

To evaluate the surface (treated with Etching, Laser, and Laser + Etching) before bonding and the fractured surface between the composite resin and dentin side after measuring shear bond strength, the representative dentin specimens were selected randomly and mounted on aluminum stubs. The samples were then sputter-coated with gold palladium and examined by scanning electron microscopy (SEM) (ISI SX-30 Cambridge, MA, USA) with 1000X magnification.

\subsection{Statistical analysis}

The obtained shear bond strength data were analyzed by two way ANOVA with a level of significance of $\mathrm{P}<0.05$.

\section{Results}

\subsection{Shear Bond Strength (SBS) evaluation}

The Mean SBS \pm SD $(\mathrm{MPa})$ of each group followed by a Single bond was $7.35 \pm 1.65,7.61 \pm 1.50$ and $6.34 \pm 1.39$, respectively, and the Mean SBS \pm SD (MPa) for each group followed by a SE bond was $7.73 \pm 1.17,7.88 \pm 2.77$, and $6.48 \pm 1.77$, respectively (Table 3 ), but there were no significant differences between the groups. The maximum and minimum SBS was observed in groups $\mathrm{E}$ and $\mathrm{C}$, respectively. The maximum and minimum SBS in the Single Bond group was observed in groups $B$ and $C$, respectively. The maximum and minimum SBS in the SE Bond group was observed in group $\mathrm{E}$ and $\mathrm{F}$, respectively (Figure 1). Some samples dislodged and de-bonded during preparation for the shear bond test due to the uneven samples distribution.

\begin{tabular}{|c|c|c|c|c|c|c|}
\hline $\begin{array}{c}\text { Adhesive } \\
\text { system }\end{array}$ & \multicolumn{3}{|c|}{ Single bond } & \multicolumn{3}{c|}{ SE bond } \\
\hline $\begin{array}{c}\text { Laser } \\
\text { intensity(W) }\end{array}$ & Control & $1.4 \mathrm{~W}$ & $2.25 \mathrm{~W}$ & Control & $1.4 \mathrm{~W}$ & $2.25 \mathrm{~W}$ \\
\hline Sample & Group A & Group B & Group C & Group D & Group E & Group F \\
\hline Mean (MPa) & 7.35 & 7.61 & 6.34 & 7.73 & 7.88 & 6.48 \\
\hline SD & 1.65 & 1.50 & 1.39 & 1.17 & 2.77 & 1.77 \\
\hline
\end{tabular}

Table 3. Comparison of the mean shear bond strength of the control and laser irradiated groups (Single bond and SE bond). Mean value (MPa) and standard deviation (SD) of the Shear Bond Strength (SBS) Test for the specimens treated with the Er,Cr:YSGG laser are shown but there were no significant differences between the groups $(\mathrm{P}>0.05)$. 


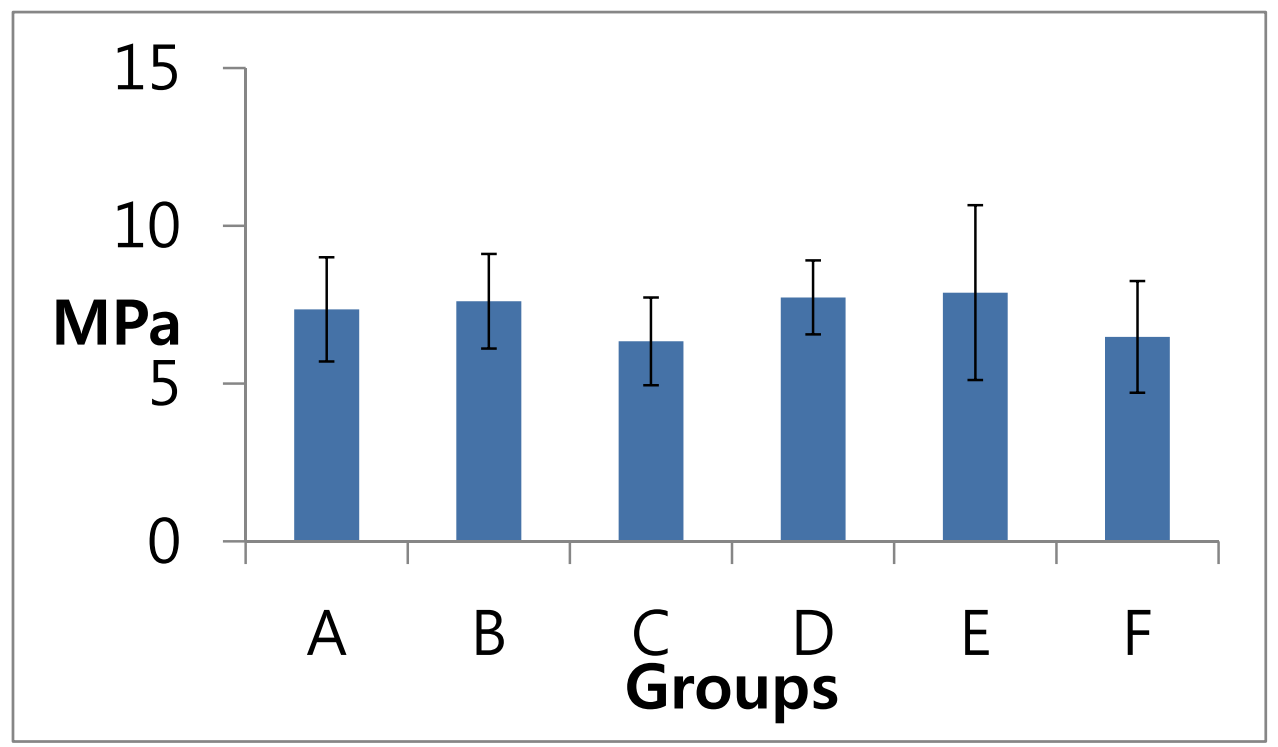

Fig. 1. Shear bond strength between the experimental groups.

\subsection{SEM (Scanning Electronic Microscopy)}

SEM revealed the fractured surface between the composite resin and dentin side, as shown in Figure 2. The representative SEM evaluation showed that thick layers of the adhesives were found on the fractured de-bonded surface of the composite resin (Figure 2-B, D, F). On the other hand, the fractured bonded surface of the dentin by the Clearfil SE bond adhesive treatment, as a result of the shear bond strength test followed by $37 \%$ phosphoric acid etching of some of the residues of the adhesives remaining on the surface of dentin side after the shear bond test (Figure 2-A, C, E).

Regarding the failure mode of the control group in the types of adhesive system, some residual chips were found (A) on the surface of dentin side fractured after $37 \%$ phosphoric acid etching and single bond adhesion but the fractured bonded surface of dentin by the Clearfil SE bond adhesive treatment as a result of the shear bond strength test followed by $37 \%$ phosphoric acid etching showed thick layers of composite resin attached to the dentin after the failure test (D).

In the irradiation groups, $1.4 \mathrm{~W}$ of irradiation followed by the Single bond procedure left the fractured dentin surface with small particles after the failure test (B). On the other hand, the fractured dentin surface irradiated with a power intensity of $2.25 \mathrm{~W}$ had exposed dentinal tubules after the test $(\mathrm{C})$. On the other hand, $1.4 \mathrm{~W}$ of power intensity irradiation followed by the SE bond procedure revealed exposed dentinal tubules after the failure test (E), whereas $2.25 \mathrm{~W}$ of power intensity irradiation followed by the SE bond procedure resulted in a thick layer of composite resin fractured cohesively on the dentin side of the fractured surface $(\mathrm{F})$. 


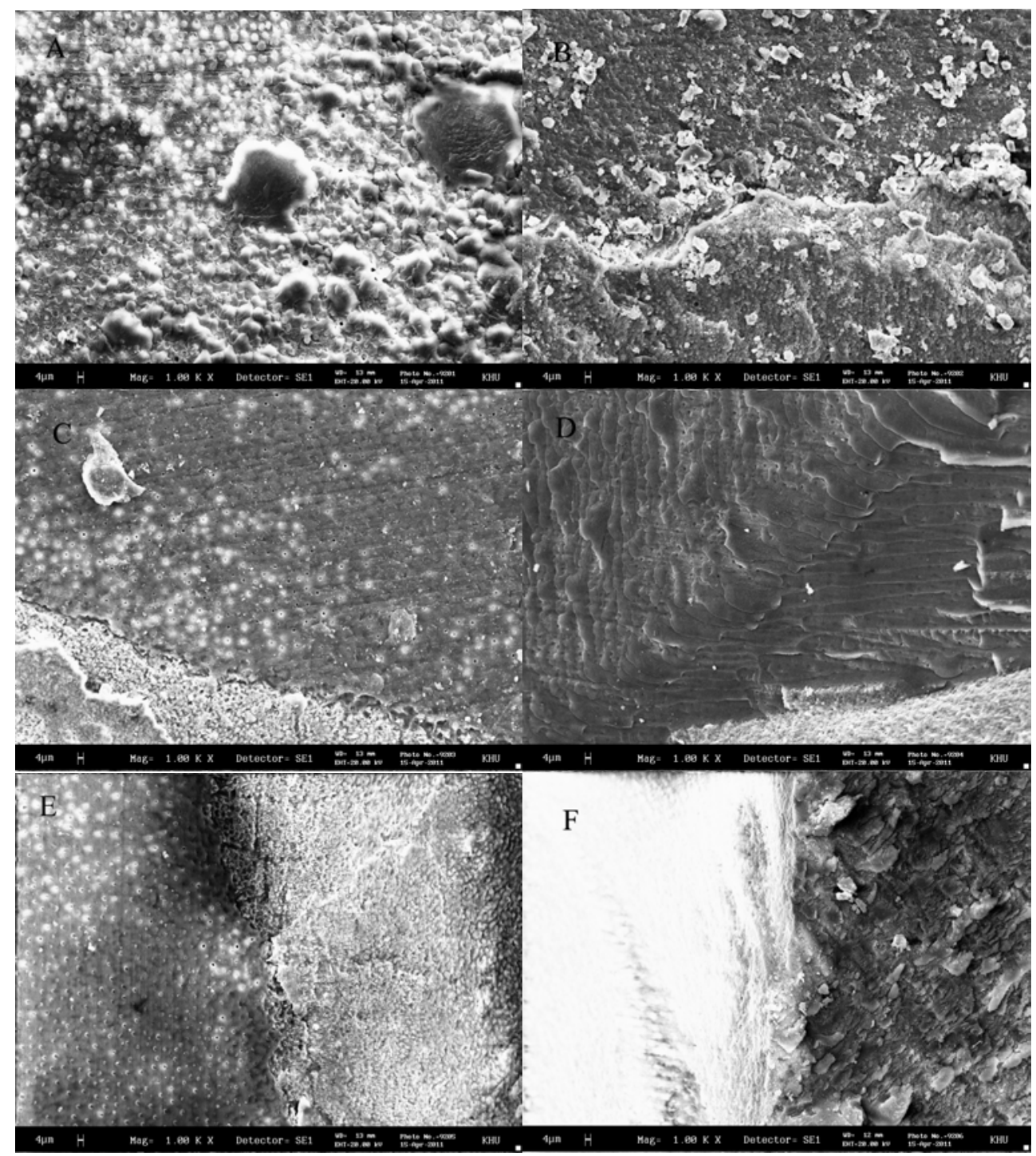

Fig. 2. SEM images (X1000) showing the fractured surface between the composite resin and dentin side. The fractured bonded surface of dentin by the single bond adhesive treatment as a result of the shear bond strength test followed by $37 \%$ phosphoric acid etching (A), and $1.4 \mathrm{~W}$ of power intensity irradiation followed by a Single bond procedure (B), and $2.25 \mathrm{~W}$ of power intensity irradiation followed by a Single bond procedure (C) were evaluated by SEM. The fractured bonded surface of the dentin by Clearfil SE bond adhesive treatment as a result of the shear bond strength test followed by 37\% phosphoric acid etching (D), and 1.4 $\mathrm{W}$ of power intensity irradiation followed by the SE bond procedure (E), and $2.25 \mathrm{~W}$ of power intensity irradiation followed by the SE bond procedure $(F)$ were evaluated by SEM. 


\section{Discussion}

Recently, Er:YAG and Cr:YSGG lasers were introduced in dentistry. For physical and medical reasons, they are used for the treatment of hard tissue. The advantage of an Erbium wave is that it is well absorbed by water and dental hard tissue. Although dentin contains a high proportion of water, the depth is shallow for laser transmission. The strong absorption of water reduces the level of heat during tooth preparation. As water absorbs laser radiation better than dental hard tissue, it reduces the increasing temperature of the tissue during the preparation. Water reaches the boiling point and causes microexposure of the tooth. This action breaks up the surrounding tissue into small pieces and dissipates them at the same time. As this explosion occurs in water, it is so-called a preparation induced by water. Although most radiation is absorbed in water, a certain amount of heat transmission is unavoidable. Therefore, a water spray is used for cooling. The proper amount of water spray prevents pulpal damage. As heat transmission normally depends on the pulse shape and pulse maintenance time, the amount of water varies according to the laser system and treatment itself. A lack of enough water spray causes pulpal damage.

In contrast to initial studies, there was no immunological difference between the laser system and conventional etching method. Moreover, the positive effect of the laser to regenerate pulp was discussed. Essentially, cavity preparation should be performed with the proper instruments with the "method of minimal pulse energy" according to the manufacturer's protocol. This is because the preparation should be performed with the capability to minimize additional damage.

The bond strength of the adhesive system is one of the major factors for the success of restorations. Therefore, this restoration parameter can be measured accurately by the bonding test. The bonding of resin composite material to the tooth structure prepared with different types of lasers has been reported (Visuri et al., 1996; Armengol et al., 1999; Martínez-Insua et al., 2000; Carrieri et al., 2007; Ekworapoj et al., 2007; Lee et al., 2007; de Carvalho et al., 2008; Gurgan et al., 2008; Chou et al., 2009). These studies reported variable results comparing the bond strengths of composite resin to a laser-prepared and acid etched dentin surface, and suggested that the laser preparation is more effective than etching in bonding strength of the composite resin to the tooth structure (Obeidi et al., 2010; Turkmen et al., 2010; Navimipour et al., 2011). This study compared the in vitro SBS of two different adhesive systems to dentin treated with an Er,Cr:YSGG laser. These results showed that the type of adhesive system had no effect on SBS, whereas the laser intensity was a criterion to be considered.

Generally, the manufacturer of Er,Cr:YSGG lasers recommended 2.25 to $2.5 \mathrm{~W}$ for laser etching but other studies used 2 to $3 \mathrm{~W}$ referring from their results of a pilot study to obtain the proper effects (Çalışkan et al., 2010). The data from this study showed that the shear bond strength (SBS) of dentin treated with $1.4 \mathrm{~W}$, was higher than that of SBS with $2.25 \mathrm{~W}$, which was recommended by the manufacturer. These results were different from other study results showing that the shear bond strength of laser etching $(1.25 \mathrm{~W}$ or $3 \mathrm{~W})$ was higher than the diamond bur (Gurgan et al., 2008). The distance between the laser tip and laser irradiated dentin surface may not be strict in this kinds of study designs. On the other hand, in this experiment, the sweeping motion of the laser irradiation $6 \mathrm{~mm}$ away from the dentin surface was used before the application of adhesive procedures to employ consistent defocused irradiation with lower intensity. Therefore, the difference in the effect between 
the distance and irradiation time of the laser could not be performed and compared with other studies in this study (Chou et al., 2009; Obeidi et al., 2009; Obeidi et al., 2010).

Based on previous studies using Er,Cr: YSGG laser irradiation on the tooth structure, normal range of power intensity $(2.5 \mathrm{~W})$ was utilized on the surface of dentin while high power intensity of the laser (higher than $3 \mathrm{~W}$ ) was more effective on the bonding strength of the enamel surface (Obeidi et al., 2010), (Dunn et al., 2005). On the other hand, Tagami et al. reported that $70 \mathrm{~mJ}(1.75 \mathrm{~W})$ of low laser intensity irradiation on the dentin surface followed by SE bond showed a higher micro shear bond strength than with $150 \mathrm{~mJ}(3 \mathrm{~W})$ (de Carvalho et al., 2008), which is similar to the present experiments. According to the manufacturer's recommendation for laser etching on dentin surface, it was decided to follow the laser protocol mode using two power intensities $(2.5 \mathrm{~W}$ and $1.25 \mathrm{~W})$. If a power intensity of 2.25 $\mathrm{W}$ and $1.4 \mathrm{~W}$ are converted to the $\mathrm{mJ}$ scale, they could be approximately $112.5 \mathrm{~mJ}$ and $70 \mathrm{~mJ}$, respectively. In the present study, $1.4 \mathrm{~W}$ of laser intensity irradiation showed the highest shear bond strength between the composite resin and bonded dentin surface with the two types of adhesive systems (Single bond and Clearfil SE bond). Consequently, the SE primer of the SE bond probably could not remove the superficial layers of the irradiated dentin completely. On the other hand, phosphoric acid of three steps adhesive or two steps adhesive could remove most of the superficial layers of the irradiated dentin. In addition, one study reported the advantages of mechanical instruments or combining acid etching and mechanical instruments in removing the superficial layers (Obeidi et al., 2009) .

With the respect to the micromorphological changes after acid etching and laser etching, SEM revealed different characteristic features from those found in conventional acid etched surfaces. The dentin surfaces irradiated with the Er,Cr:YSGG laser had a scaly, irregular, and rugged appearance compared to the acid etched dentin surface (Chou et al., 2009). In addition, with the higher laser intensity or longer irradiation time, the condition was worse in terms of the irregularity of the dentin surface, which has a close relationship with the bonding strength of the composite resin to dentin.

The control groups showed a higher SBS than the $2.25 \mathrm{~W}$ of laser irradiated groups in all bonding systems, but, SEM evaluation revealed more adhesive chips remaining on the control group than on the $2.25 \mathrm{~W}$ laser irradiated group. On the other hand, thick, rough, and irregular collapsed composite resins were estimated on both the control and $2.25 \mathrm{~W}$ laser irradiated groups. SEM examinations of the two kinds of laser intensity irradiation (1.4 $\mathrm{W}$ and $2.25 \mathrm{~W}$ ) revealed that the $1.4 \mathrm{~W}$ laser intensity group had more adhesive chips remaining on the dentin than the $2.25 \mathrm{~W}$ laser group in the Single bond adhesive system, which is opposite to that observed in the Clearfil SE bond system.

One possible explanation is that the thermomechanical effects of higher laser intensity probably have extended into the subsurface dentin and undermined the integrity of the resin-dentin interface resulting in a lower bond strength. The formation of fissures or cracks in the subsurface dentin might be a start point for the failure of resin-dentin adhesion. Obviously, all irradiated groups were affected by thermo-mechanical effect, but $1.4 \mathrm{~W}$ and $2.25 \mathrm{~W}$ were all affected by thermomechanical effects. On the other hand, $1.4 \mathrm{~W}$ laser intensity might not be seriously affected. Laser irradiation with a high intensity may obstruct the dentinal tubules by melting and fail to produce a good hybrid layer. Whereas, laser irradiation with a low intensity may leave the dentinal tubule open and facilitate the infiltration of bonding agent. This may account for the lower SBS values with $2.25 \mathrm{~W}$ irradiated dentin than with $1.4 \mathrm{~W}$ laser intensity. 
These results suggest that the acid etching of lased dentin can reinforce the hybrid layer and formation of resin tags, but the acidic monomer of SE bonds cannot function at its best due to the obstruction of dentinal tubules and denatured collagen fibrils network and the absence of smear layer. These results were not the same as expected. A self etching adhesive system and two steps adhesive system showed a similar SBS because the resin tags only contribute to the bond strength in small portions $(15 \%)$ and the poorer quality of the hybrid layer appears to be the main reason for the lower bond strength.

\section{Conclusion}

An Er,Cr:YSGG laser was used to determine if the laser can increase the shear bond strength between the composite resin and surface treated dentine surfaces. On the other hand, the pretreatment of dentin with an Er,Cr:YSGG laser does not affect the shear bond strength of the two different adhesive systems under these experimental conditions. In addition, the shear bond strength of two different adhesive systems in dentin treated with a $1.4 \mathrm{~W}$ laser intensity was higher than that treated with $2.25 \mathrm{~W}$ but the difference was not significant.

\section{Acknowledgment}

This study was supported in part by a grant from Kyung Hee University in 2006 (KHU20060930) and by the Basic Science Research Program through the National Research Foundation of Korea (NRF) funded by the Ministry of Education, Science and Technology (NRF-20100023448).

\section{References}

Abdalla AI, Davidson CL (1998) Bonding efficiency and interfacial morphology of one-bottle adhesives to contaminated dentin surfaces. Am J Dent, Vol. 11, No. 6, pp. 281-285, ISSN 0894-8275

Armengol V, Jean A, Rohanizadeh R, Hamel H (1999) Scanning electron microscopic analysis of diseased and healthy dental hard tissues after Er: YAG laser irradiation: in vitro study. J Endod, Vol. 25, No. 8, pp. 543-546, ISSN 0099-2399

Çalışkan MK, Parlar NK, Oruçoğlu H, Aydın B (2010) Apical microleakage of root-end cavities prepared by Er, Cr: YSGG laser. Lasers in Medical Science, Vol. 25, No. 1, pp. 145-150, ISSN 0268-8921

Carrieri TCD, Freitas PM, Navarro RS, P. Eduardo C, Mori M (2007) Adhesion of composite luting cement to Er:YAG-laser-treated dentin. Lasers in Medical Science, Vol. 22, No. 3, pp. 165-170, ISSN 0268-8921

Chou JC, Chen CC, Ding SJ (2009) Effect of Er, Cr: YSGG laser parameters on shear bond strength and microstructure of dentine. Photomedicine and Laser Surgery, Vol. 27, No. 3, pp. 481-486, ISSN 1549-5418

de Carvalho RCR, de Freitas PM, Otsuki M, de Eduardo CP, Tagami J (2008) Micro-shear bond strength of Er: YAG-laser-treated dentin. Lasers in Medical Science, Vol. 23, No. 2, pp. 117-124, ISSN 0268-8921

Dunn WJ, Davis JT, Bush AC (2005) Shear bond strength and SEM evaluation of composite bonded to Er:YAG laser-prepared dentin and enamel. Dent Mater, Vol. 21, No. 7, pp. 616-624, ISSN 0287-4547 
Ekworapoj P, Sidhu SK, McCabe JF (2007) Effect of different power parameters of Er, Cr: YSGG laser on human dentine. Lasers in Medical Science, Vol. 22, No. 3, pp. 175-182, ISSN 0268-8921

Gurgan S, Kiremitci A, Cakir FY et al. (2008) Shear Bond Strength of Composite Bonded to Er,Cr:YSGG Laser-Prepared Dentin. Photomedicine and Laser Surgery, Vol. 26, No. 5, pp. 495-500, ISSN 1549-5418

Lee BS, Lin PY, Chen MH et al. (2007) Tensile bond strength of Er, Cr: YSGG laser-irradiated human dentin and analysis of dentin-resin interface. Dental Materials, Vol. 23, No. 5, pp. 570-578, ISSN 0109-5641

Martínez-Insua A, da Silva Dominguez L, Rivera FG, Santana-Penín UA (2000) Differences in bonding to acid-etched or Er: YAG-laser-treated enamel and dentin surfaces. The Journal of prosthetic dentistry, Vol. 84, No. 3, pp. 280-288, ISSN 1097-6841

Navimipour EJ, Oskoee SS, Oskoee PA, Bahari M, Rikhtegaran S, Ghojazadeh M (2011) Effect of acid and laser etching on shear bond strength of conventional and resinmodified glass-ionomer cements to composite resin. Lasers in Medical Science, pp. 17, ISSN 0268-8921

Obeidi A, Liu P-R, Ramp LC, Beck P, Gutknecht N (2010) Acid-etch interval and shear bond strength of Er,Cr:YSGG laser-prepared enamel and dentin. Lasers in Medical Science, Vol. 25, No. 3, pp. 363-369, ISSN 0268-8921

Obeidi A, McCracken MS, Liu PR, Litaker MS, Beck P, Rahemtulla F (2009) Enhancement of bonding to enamel and dentin prepared by Er,Cr:YSGG laser. Lasers Surg Med, Vol. 41, No. 6, pp. 454-462, ISSN 1096-9101

Perdigao J, May KN, Jr., Wilder AD, Jr., Lopes M (2000) The effect of depth of dentin demineralization on bond strengths and morphology of the hybrid layer. Oper Dent, Vol. 25, No. 3, pp. 186-194, ISSN 0361-7734

Turkmen C, Sazak-Ovecoglu H, Gunday M, Gungor G, Durkan M, Oksuz M (2010) Shear Bond Strength Of Composite Bonded With Three Adhesives To Er, Cr: YSGG Laser-Prepared Enamel. Quintessence International, Vol.41, pp. e119-e124, ISSN 00336572

Visuri SR, Gilbert JL, Wright DD, Wigdor HA, Walsh JT (1996) Shear Strength of Composite Bonded to Er:YAG Laser-prepared Dentin. Journal of Dental Research, Vol. 75, No. 1, pp. 599-605, ISSN 1544-0591 


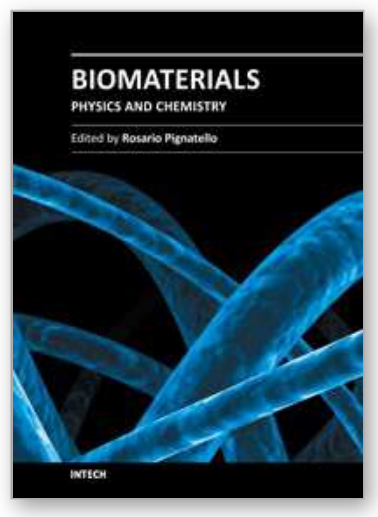

\author{
Biomaterials - Physics and Chemistry \\ Edited by Prof. Rosario Pignatello
}

ISBN 978-953-307-418-4

Hard cover, 490 pages

Publisher InTech

Published online 14, November, 2011

Published in print edition November, 2011

These contribution books collect reviews and original articles from eminent experts working in the interdisciplinary arena of biomaterial development and use. From their direct and recent experience, the readers can achieve a wide vision on the new and ongoing potentialities of different synthetic and engineered biomaterials. Contributions were selected not based on a direct market or clinical interest, but based on results coming from very fundamental studies. This too will allow to gain a more general view of what and how the various biomaterials can do and work for, along with the methodologies necessary to design, develop and characterize them, without the restrictions necessarily imposed by industrial or profit concerns. The chapters have been arranged to give readers an organized view of this research area. In particular, this book contains 25 chapters related to recent researches on new and known materials, with a particular attention to their physical, mechanical and chemical characterization, along with biocompatibility and hystopathological studies. Readers will be guided inside the range of disciplines and design methodologies used to develope biomaterials possessing the physical and biological properties needed for specific medical and clinical applications.

\title{
How to reference
}

In order to correctly reference this scholarly work, feel free to copy and paste the following:

Eun Mi Rhim, Sungyoon Huh, Duck Su Kim, Sun-Young Kim, Su-Jin Ahn, Kyung Lhi Kang and Sang Hyuk Park (2011). Effect of the Er, Cr: YSGG Laser Parameters on Shear Bond Strength and Microstructure on Human Dentin Surface, Biomaterials - Physics and Chemistry, Prof. Rosario Pignatello (Ed.), ISBN: 978-953-307-4184, InTech, Available from: http://www.intechopen.com/books/biomaterials-physics-and-chemistry/effect-of-theer-cr-ysgg-laser-parameters-on-shear-bond-strength-and-microstructure-on-human-dentin-

\section{INTECH}

open science | open minds

\section{InTech Europe}

University Campus STeP Ri

Slavka Krautzeka 83/A

51000 Rijeka, Croatia

Phone: +385 (51) 770447

Fax: +385 (51) 686166

www.intechopen.com

\section{InTech China}

Unit 405, Office Block, Hotel Equatorial Shanghai

No.65, Yan An Road (West), Shanghai, 200040, China

中国上海市延安西路65号上海国际贵都大饭店办公楼405单元

Phone: +86-21-62489820

Fax: +86-21-62489821 
(C) 2011 The Author(s). Licensee IntechOpen. This is an open access article distributed under the terms of the Creative Commons Attribution 3.0 License, which permits unrestricted use, distribution, and reproduction in any medium, provided the original work is properly cited. 